\title{
Cabildo, negociación y vino de cocos: el caso de la villa de Colima en el siglo XVII/
} Government, Negotiation and the Coconut Liquor: the Town Council of Colima during the Seventeenth Century

\author{
Claudia Paulina Machuca Chávez \\ CIESAS Occidente, \\ Guadalajara, Jal., México
}

Después de una intensa producción de cacao durante el siglo XVI, la villa de Colima de la Nueva España sufrió la pérdida de este cultivo por causas climáticas y por el apoyo preferente de la Corona a los sembradios de cacao en Sudamérica. Para el beneficio de sus habitantes, la llegada de "indios chinos" o asiáticos a la villa de Colima propició el desarrollo de una pequeña industria, la del vino de cocos, que a la postre se convertiría en la principal actividad económica de la villa durante todo el siglo XVII. Aunque en un principio se consideró como una "bebida de la tierra" -y por consiguiente, prohibida-, el Cabildo colimense fue una institución clave en la negociación con los virreyes y la Real Audiencia de México para conseguir licencias que permitieran no sólo su fabricación, sino su eventual distribución en el mercado regional novohispano.

Palabras Clave: Colima; vino de cocos; "indios chinos”; Cabildo; negociación.

After a huge production of cocoa plantings during the Sixteenth century, the town of Colima in the New Spain lost this culturing because of climate difficulties and because of the preference that the Crown made on cocoa plantings in South America. For the benefit of its settlers, the arrival of "indios chinos", an Asian community at the town of Colima permitted the development of a small industry based on a coconut drink — "vino de cocos"-, which became the most important economic activity during the Seventeenth century. Even when it was considered a "native drink" at first — and therefore forbidden - the town council of Colima was a fundamental institution in the negotiation with viceroys and the Real Audiencia of Mexico in order to get licenses that permitted not only its elaboration but also its distribution alongside a regional market.

Keywords: Colima; Coconut Drink; “indios chinos”; Town Council; Negotiation. 
Durante el siglo XVII, el vino de cocos fue una de las actividades económicas más importantes de la provincia de Colima de la Nueva España. En su momento de mayor apogeo, casi todo el vecindario colimense se había volcado en la siembra de palmas en las haciendas donde también se practicaban otros cultivos, como el cacao y la caña. El vino de cocos fue una de las "bebidas de la tierra" con mayor éxito en su región y, aunque no alcanzó el nivel de consumo de otras bebidas como el pulque, su ámbito de distribución se extendía a algunas poblaciones de la Nueva Galicia, Michoacán y la capital del Virreinato.

El objetivo de este texto es explicar cómo el Cabildo de la villa de Colima intervino estratégicamente en la elaboración y distribución del vino de cocos, al negociar el permiso de su libre fabricación con la Real Audiencia de México y los virreyes de turno. Para ello, la corporación municipal colimense empleó herramientas jurídicas basadas en la justicia clemente, es decir, en aquella que aludía a la compasión o la moderación de las autoridades reales.

\section{La villa de Colima}

Esta villa se fundó en 1523. Por su situación geográfica, fuera de la ruta de la plata y alejada del polo de poder central en la ciudad de México, gozó de un amplio margen de autonomía frente a las presiones superiores de la burocracia imperial. Situada en el finisterre de la Nueva España, justo en el límite con la Nueva Galicia y sobre la Mar del Sur, Colima siguió el rumbo de otras ciudades hispanoamericanas de frontera: vecindarios pequeños, población indígena abundante en sus alrededores y relaciones de parentesco directo con los primeros conquistadores. ${ }^{1}$ La primera colonia colimense estuvo poblada por 145 españoles, ${ }^{2}$ número que en los años posteriores disminuyó paulatinamente. Hacia 1612 había alrededor de 100 vecinos, mientras que una década más tarde no pasarían de noventa. ${ }^{3}$

1 De la Peña, José F.: Oligarquía y propiedad en la Nueva España, Fondo de Cultura Económica, México, 1983, págs. 54-71.

2 Sauer, Carl: Colima of New Spain in the Sixteenth Century, University of California in Berkeley and Los Angeles, Los Angeles, 1948, pág. 85.

3 De la Peña, Oligarquía, pág. 67. 
La temprana fundación de Colima se explica a partir de los planes que Hernán Cortés y sus hombres tenían por conquistar los territorios septentrionales que bordeaban la costa de la Mar del Sur en la Nueva España. La villa colimense sería un punto neurálgico desde donde se llevarían a cabo estas expediciones. Fue así como Francisco Cortés de Buenaventura pensó en erigir, en la década de 1520, un extenso territorio llamado el Gran Colima que abarcaría, en su momento de mayor amplitud, "desde las riberas del Río Grande de Santiago, en Nayarit, hasta por lo menos Acapulco";4 esto es, los actuales estados de Nayarit, Jalisco, Colima, Michoacán y Guerrero.

El escenario del Gran Colima era prometedor. Sin embargo, durante el periodo de 1530-1533, las conquistas del acérrimo enemigo de Hernán Cortés, Nuño de Beltrán de Guzmán, no sólo interrumpieron el crecimiento de la provincia colimense, sino que además la redujeron considerablemente. Ese mismo conquistador habría de fundar entonces la Nueva Galicia y, con ello, poner fin a cualquier intento de expansión de la Nueva España en su parte occidental. Colima quedó, entonces, como se ha señalado,en el finisterre de la Nueva España.

\section{El surgimiento de una nueva industria}

La fabricación del vino de cocos fue una técnica de origen asiático, incorporada en la sociedad colimense desde finales del siglo XVI, época en que los documentos ya dan las primeras noticias de "indios chinos", originarios del sudeste de Asia y que año tras año desembarcaban en los puertos de Colima, aprovechando la ruta del galeón de Manila. Incluso la semilla del coco, que ahora se observa como una parte inherente en el paisaje a lo largo del litoral del Pacífico mexicano, fue introducida en la Nueva España por Álvaro de Mendaña, en 1569, después de su travesía por el sudeste asiático.

La técnica del vino de cocos llegó a Colima justo cuando los sembradíos de cacao empezaban a declinar. La producción y comercialización de ese producto se había posicionado como la actividad económica más

4 Romero de Solís, José Miguel: Rescoldo de quimeras: Colima desta Nueva España de las Indias del Mar Océano (1523-1600), Tesis de doctorado, El Colegio de Michoacán, Zamora, Mich., 2000, pág. 42. 
importante para los vecinos de Colima durante la segunda mitad del siglo XVI. José F. de la Peña lo destacó como un "monocultivo" que, junto con otras plantaciones, ganado y salinas, constituían las propiedades básicas de los vecinos. ${ }^{5}$ Pero a medida que la Corona fomentó la producción del cacao sudamericano, generalmente de mayor calidad, los colimenses optaron por la siembra de otros cultivos, como las palmeras de origen asiático. Las inclemencias del clima fueron otro factor que jugó en contra del cacao, pues los constantes huracanes que azotaban la provincia de Colima arrasaban las haciendas de cacaotales.

Los colimenses aprendieron la técnica para fabricar el ya citado vino de cocos —en plural, como se acostumbraba en la época— de los asiáticos que arribaron a la Mar del Sur desde finales del siglo XVI. Antes de llegar a su destino final, el puerto de Acapulco, el Galeón de Manila hacía una escala en el puerto de Salagua, Colima, donde desembarcaba mercancía de contrabando ${ }^{6}$ y donde muchos "indios chinos" se aventuraban a lo que esta tierra les podía ofrecer.

Los cocoteros comenzaban a dar frutos en apenas cinco o seis años, y entraban en un periodo de plena producción a los diez o doce años. La inflorescencia llevaba de cinco a quince frutos y un racimo podía tener de 10 hasta 30 cocos en un periodo de recolección de cada tres meses. ${ }^{7}$ Las fábricas de vino de cocos, llamadas también "haciendas de palmas de beneficio", contaban hasta con 400 palmeras en producción. ${ }^{8}$ La palmera no requería de un cuidado especial, como el cacao, por eso la inversión de capital era bastante baja, como en el caso de las haciendas pulqueras, donde se requería de muy poca agua. ${ }^{9}$

5 De la Peña, Oligarquía.

6 En la relación de Documentos varios relativos a Nueva España se describe cómo en el puerto de Colima desembarcaba el gentilhombre del galeón de Filipinas para dar aviso al virrey sobre el estado de la embarcación, y con más propiedad diré que un mercader cargado de todos los géneros sin pagar derecho alguno a su majestad los cuales venden en el camino hasta llegar a México por hacer su viaje con la lentitud que a este fin conviene (Real Academia de la Historia, Madrid, Colección Muñoz, Documentos varios relativos a Nueva España, N. 798, f. 373 v. , s/f).

7 Guedea y Castañeda, José Óscar: Las haciendas en Colima. Una excepción al modelo establecido en otros Estados de la República Mexicana, [s/n], Colima, 1999, pág. 59.

8 De la Madrid Castro, Alfonso: Apuntes históricos sobre Colima, siglos XVI-XX, Gobierno del Estado de Colima-Universidad de Colima-Archivo Histórico del Municipio de Colima (AHMC), Colima, 1998, pág. 104.

9 Rendón Garcini, Ricardo: Haciendas de México, Fondo Cultural Banamex, A. C., México, 1994, pág. 210. 
Aunque no se sabe con exactitud la cantidad de palmas que se plantaron a fines del siglo XVI y principios del XVII, su valor en conjunto oscilaba alrededor de los 100.000 ducados en el año de $1612^{10} \mathrm{y}$, "en el supuesto de que los cocoteros tuvieran el mismo valor que los árboles de cacao, 1 peso por árbol, esto significaría la existencia de por lo menos 138 mil palmas" en ese mismo año. ${ }^{11}$ Fray Antonio Tello describió en su Crónica miscelánea el proceso de fabricación del vino de cocos:

[...] el vástago que arroja la palma en que había de dar su fruto, lo atan muy bien con unos cordeles, dando mucha vueltas, y le van cortando poco a poco, una vez en la mañana y otra a la tarde, teniendo colgado de él un calabazo o vaso, en que va destilando el agua, que llaman tuba, la cual acabada de salir, es una bebida de mucho regalo, dulce y sabrosa; después lo echan en unas vasijas para que se acede un poco, y luego lo destilan por alambiques, y así lo destilado, es el vino; y si lo sacan con cuidado es fortísimo y como el aguardiente de Castilla. ${ }^{12}$

Así como el cacao había sido un monocultivo en Colima durante el siglo XVI, el vino de cocos se convirtió en la actividad económica más rentable del siglo XVII. Un alto porcentaje del vecindario español de Colima —entre cien y ciento cincuenta - poseía haciendas de palmas para el beneficio del vino.

El vino de cocos llegó a comercializarse y distribuirse en lugares como Michoacán, la ciudad de México, San Luis Potosí, Pachuca, Guachinango, Guanajuato, Zacatecas y Parral. En las fiestas patronales de Pátzcuaro, por ejemplo, se elaboraba una comida "que iba regada con abundante vino de cocos de Colima". ${ }^{13}$ Era llevado en botijas peruleras, a lomo de mula, y su precio se acercaba a dos reales el cuarto, cuando el vino de Castilla se vendía en 3 reales el cuartillo. ${ }^{14}$ El precio de una botija de vino de cocos en 1638 era de un peso, mientras que una carga — seis botijas- se vendía en seis pesos de oro común. El consumo interno y la expor-

10 Sevilla del Río, Felipe: Provança de la villa de Colima en su defensa ante un mandamiento de la Real Audiencia de México que ordenaba la tala total de los palmares colimenses. Año de 1612, Jus, México, 1977.

11 Reyes Garza, Juan Carlos: La antigua provincia de Colima, siglos XVI al XVIII, Universidad de Colima-Gobierno del Estado de Colima-Consejo Nacional para la Cultura y las Artes, Colima, 1995, pág. 158.

12 Tello, Fray Antonio: Crónica miscelánea de la Sancta Provincia de Xalisco... Gobierno del Estado de Jalisco-Universidad de Guadalajara-Instituto Nacional de Antropología e Historia-Instituto Jalisciense de Antropología e Historia, Serie Historia, 9, Guadalajara, 1985, pág. 381.

13 Castro Gutiérrez, Felipe: "Alborotos y siniestras relaciones: la república de indios de Pátzcuaro colonial”, Relaciones, N. ${ }^{\circ}$ 89, Zamora, Mich., Invierno de 2003, pág. 204.

14 Sevilla, Provança. 
tación del aguardiente se estimaban en diez mil botijas anuales, con un precio de 25.000 pesos de oro común. ${ }^{15}$

La industria del vino de cocos dio paso a la creación de otros sectores y actividades económicas dependientes, como los fabricantes de barriles de madera para el aguardiente. En 1639, por ejemplo, existía la figura del cobrador del diezmo del vino de cocos, ${ }^{16}$ lo que muestra el arraigo de esta actividad en la vida cotidiana colimense. Los testamentos son una fuente invaluable que descubre la gran cantidad de utensilios relacionados con el vino de cocos entre los bienes de los colimenses de la época.

Bartolomé Núñez, quien falleció en abril de 1647, dejó en su hacienda de San Cristóbal un horno con dos cazos para hacer vino, con su dotación de barriles, once cántaros para cocer la tuba, cien botijas en que se almacenaba el vino y treinta y dos botijas de vino de $\operatorname{cocos}{ }^{17}$ Francisca Martha, india china, dejó entre sus bienes un horno para cocer vino, botijas de vino y cántaros para la tuba (ver cuadros 1 y 2).

\section{CUADRo 1}

\section{INVENTARIO DE BIENES DE FRANCISCA MARTHA, INDIA CHINA}

(fragmento)

3 bestias mulares de carga y silla

18 bestias caballares mansas

un horno de cocer vino con dos casos viejos y su barril

5 botijas castellanas

6 cántaros en que se echa la tuba

2 botijas llenas de vino

un vinatero llamado Juan Alonso que debe cuarenta y un pesos

un faldellín de pana verde viejo

unas ollas

un candelero de azófar

una fresadilla

unos manteles viejos y rotos

Fuente: Archivo Histórico del Municipio de Colima (AHMC), 1664, caja B-30, exp. 23.

15 Guedea, Las haciendas, pág. 67.

16 Ibidem, pág. 64.

17 De la Madrid, Apuntes históricos, pág. 105. 


\section{Gobernantes y empresarios}

Las autoridades del gobierno local de Colima poseían haciendas de palmas para fabricar vino de cocos, en una época en que las elites políticas eran, al mismo tiempo, las elites económicas. A pesar de los esfuerzos de los alcaldes mayores por evitar la fabricación y distribución del aguardiente, los vecinos colimenses, entre ellos algunos miembros del propio Cabildo, hicieron caso omiso de las prohibiciones.

Algunos alcaldes ordinarios que produjeron vino de cocos en diferentes tiempos fueron Rodrigo de Brizuela y Jorge Carrillo de Guzmán; el primero tenía "palmas de beneficio de hacer vino" con las cuales producía cincuenta arrobas de vino anualmente, obteniendo por ellas ciento cincuenta pesos. ${ }^{18}$ Jorge Carrillo de Guzmán, por su parte, heredó una huerta de cacao en el valle de Caxitlán, misma que aprovechaba para la siembra de palmares. Así, “de los cocos bien beneficiados sacaré cada año doscientas botijas de vino, que valen seiscientos pesos". ${ }^{19}$

El alcalde Rodrigo de Brizuela declaró que los palmares que tenía en posesión le daban "quince palmas de beneficio de hacer vino, que beneficiándolas dan cincuenta arrobas de vino cada año, que valen a tres pessos arroba, montando ciento y cincuenta pessos". ${ }^{20}$ Andrés de Castilla Montemayor sacaba cien botijas anuales de vino de cocos, gracias a una huerta que recibió en dote y que él fue mejorando poco a poco. ${ }^{21}$ Otros alcaldes que se beneficiaron de la producción de este tipo de vino fueron Alonso Álvarez de Espinosa $(1613,1616),{ }^{22}$ Hernán Gómez Machorro (1617), ${ }^{23}$ Juan Preciado (1619) ${ }^{24}$ y Luis de Solórzano. ${ }^{25}$

Para Alfonso de la Madrid, es difícil que durante el siglo XVII hubieran existido en Colima hacendados con grandes extensiones de tierra, pues las fronteras naturales de los volcanes al norte, el mar al sur y el Río

18 Archivo General de Indias (AGI), México, 262, N. ${ }^{\circ}$ 825, en Reyes Garza, Juan Carlos: Por mandato de su Majestad. Inventarios de bienes de autoridades de Colima, 1622, Gobierno del Estado de Colima, Colima, 2000, pág. 41.

19 Ibidem, en Reyes, Por mandato, pág. 46.

20 Ibidem, en Ibidem, pág. 41.

21 Ibidem, ․․ ${ }^{\circ} 818$, en Ibidem, págs. 61-65.

22 AGI, México, 262, N. ${ }^{\circ} 813$, en Ibidem, págs. 19-26.

23 Ibidem, N. ${ }^{\circ} 842$, en Ibidem, págs. 107-111.

24 Ibidem, N. ${ }^{\circ} 822$, en Ibidem, pág. 150.

25 Ibidem, N. ${ }^{\circ} 840$, en Ibidem, pág. 169. 
Grande al poniente evitaron la acumulación de suelo como en otras partes de la Nueva España. ${ }^{26}$

\section{La bebida prohibida}

El vino de cocos experimentó la suerte de otras "bebidas de la tierra" que se producían en la Nueva España: una constante presión para erradicarlas o, en el último de los casos, para incorporarlas al sistema de pago de alcabalas que reportaran un porcentaje de los ingresos en las arcas reales. ${ }^{27}$ Aunque las haciendas de palmas figuraban ya en el paisaje colimense desde finales del siglo XVI, no fue hasta el cambio de siglo cuando se estableció una incipiente industria del vino de cocos. Su fabricación estaba en manos de los vecinos españoles en las también llamadas "huertas de beneficio de hacer palmas", donde la principal mano de obra eran los "indios chinos".

Una de las autoridades del Cabildo con más renombre en la localidad, Diego Mejía de la Torre, alcalde ordinario en varias ocasiones y nieto del gobernador de la Nueva Galicia, Melchor Pérez de la Torre, fue uno de los primeros fabricantes del aguardiente. Mejía se valió del cargo que desempeñaba como alcalde ordinario, en 1602, para distribuir la bebida a lo largo de la provincia. En ese mismo año llegó a Colima un prominente mercader de la ciudad de México que, entre otras cosas, trajinaba vino de Castilla. Su nombre era Mateo de Zárate, quien al percatarse del negocio del alcalde de Colima, lo denunció porque "estando prohibido no se haga vino de cocos en esta dicha villa", lo fabricaba en gran cantidad y en contravención a la calidad de su oficio como juez. ${ }^{28}$

Las noticias sobre el vino de cocos debieron llegar a oídos de las autoridades centrales y los alcaldes mayores de Colima de los primeros años del siglo XVII tuvieron como prioridad la erradicación de este aguardiente. Tal fue el caso de Luis Hurtado de Mendoza (1600-1603), Francisco Escudero

26 De la Madrid Castro, Alfonso: Haciendas y hacendados de Colima, Edición de Julia Preciado Zamora y José Miguel Romero de Solís, AHMC, Colección Pretextos, Textos y Contextos, 18, Colima, 1999, pág. 29.

27 Tal fue el caso del pulque, que por mucho tiempo se mantuvo como bebida prohibida hasta la creación de su estanco. Véase Hernández Palomo, José J.: La renta del pulque en Nueva España, 1663-1810, Escuela de Estudios Hispano-Americanos, Sevilla, 1979.

28 AHMC, caja B-20, exp. 1, pos. 22. Colima, 26 de septiembre de 1602. 
Figueroa (1603-1605) y Juan de Rivera (1605-1607), quienes tomaron medidas enérgicas para evitar que la bebida llegara, sobre todo, a los pueblos de indios. ${ }^{29}$

\author{
CUADRO 2 \\ BIENES DE LORENZO DE AGUILAR, INDIO CHINO ABINTESTATO \\ (fragmento)
}

Tres cuchillos de palmas viejos y un machete

Una coa

Unos papeles sueltos que estaban en este legajo

Una caja vieja quebrada

Dos yeguas mansas, una castaña

Este inventario se realizó en presencia de los chinos de la hacienda de palmas de Sinacamitlán, propiedad del escribano Clemente Hidalgo de Agüero: Juan de la Cruz, Francisco Diego, Juan de Vega, Miguel Gómez y Francisco Melchor.

Fuente: AHMC, caja B-29, exp. 20. Colima, 1644.

La industria del vino de cocos no sólo pervivió a pesar de las constantes prohibiciones, sino que además fue ganando terreno en la localidad y pronto se consolidó como la actividad económica más importante de los vecinos españoles. Los reportes de su venta y distribución que empezaban a crear un mercado regional motivaron al virrey Luis de Velasco el Joven a expedir una ordenanza, en marzo de 1610, para prohibirlo de manera definitiva. El informe que había llegado a México manifestaba que en las provincias de Colima y Zacatula se había introducido "una bebida de vino que hacen de cocos de palmas" y que era tal su abundancia que tan sólo en uno de los pueblos había sesenta tabernas donde públicamente se "acuartillaba" y vendía. ${ }^{30}$

También se discutía que la salud de los naturales se veía perjudicada porque el bajo costo del aguardiente permitía que lo bebieran en exceso.

29 Ibidem, caja B-25, exp. 12, pos. 3. Colima, 1605.

30 Archivo General de la Nación, México (AGN), Ordenanzas, vol. 1, exp. 144, f. 130v. México, 29 de marzo de 1610. 
Pero uno de los puntos que más preocupaba era que el vino de cocos "estorbaba" la venta del vino de Castilla, lo cual iba en detrimento de los derechos de Su Majestad, al grado que incluso en las sacristías de los pueblos "podrían mezclar este dicho vino de cocos con el de castilla, que está dedicado para celebrar los ministros de doctrina" ${ }^{31}$ Luís de Velasco decretó severas penas para quienes vendieran pública o secretamente el aguardiente de palmas: mil ducados de Castilla para los españoles, cien azotes y pena de destierro para mestizos, negros o mulatos, y cincuenta azotes atados a un palo de la plaza pública a los indios. ${ }^{32}$

Cuando el año de 1612 estaba ya en puerta, la Real Audiencia de México determinó que, ante la inobediencia de los vecinos de Colima y debido a los argumentos presentados dos años antes sobre la mortandad de indios a causa del vino de cocos, se debían talar todos los palmares de la provincia colimense, pues sólo de esta manera acabarían con el problema. Para entonces, las haciendas dejaban de producir cacao para dedicarse de lleno a la elaboración del aguardiente, y entre los vecinos volcados a su fabricación figuraban algunos miembros del Cabildo.

A partir de 1612, el Ayuntamiento de Colima se convirtió en una institución clave para defender los intereses económicos que el vino de cocos empezaba a redituar. Después de conocer la resolución de la Audiencia de México sobre cortar los palmares, los capitulares implementaron el recurso jurídico "se obedece pero no se cumple". En sesión de Cabildo de ese año, se redactaron diez puntos a través de los cuales se explicaban a las autoridades centrales los motivos para no echar abajo las plantaciones. En el documento que resultó de la junta, titulado Provança de la villa de Colima en defensa de sus palmares ${ }^{33}$ se argumentó que el vino de cocos gozaba de propiedades curativas al revertir el veneno contra picadura de alacranes, sanar heridas graves y "dificultosas" y eliminar problemas gastrointestinales.

En la Provança se explicaba, además, que el vino de cocos no causaba la muerte de los indios, sino que ellos fabricaban sus propios aguardientes "para sus borracheras" con cañas, maguey, ciruelas, maíz y otras raíces. Por tanto, "los brebajes de que así usan los dichos yndios son de suyo nosibos y pestilenciales, de los quales y del muncho acseso con que los beben

31 Ibidem. México, 29 de marzo de 1610.

32 Ibidem, f. 131. México, 29 de marzo de 1610.

33 Sevilla, Provança. 
se les recrecen sus enfermedades. ${ }^{34}$ La elaboración de vino casero a partir de plantas al alcance de los indios debió ser una situación generalizada en el Virreinato. En Zacatecas, por ejemplo, los indios obtenían pulque a partir de aguamiel y miel de maguey, tras un procedimiento de fermentación, ${ }^{35}$ por lo que allá también se emitieron ordenanzas especiales para frenar la fabricación de la bebida.

Otro argumento fue que el vino de cocos era un aguardiente medicinal, usado para curar enfermedades y que de ninguna manera resultaba nocivo para la salud. Dentro de la astucia del Cabildo para defender este vino, estuvo el presentar como testigo a un cirujano de la villa de Colima, Martín Hernández, quien afirmó:

este testigo por espirencia grande que tiene, ser muy saludable y medicinal [el vino de cocos], la qual de hordinario aplica para curar heridas y enfermedades graves y dificultosas, en que a fecho yspirencia así por bebida como por laboratorios y otros remedios que, por ser tantos no los espressa, con la qual a dado por sanas a muchas personas y sin número, y señaladamente a yndios a los quales en esta provincia a curado con la dicha aguardiente. Y tomada por beuida lo es muy buena y saludable, porque corta las flemas, provoca sudores contra ponzoña de alacranes y otras sabandijas. ${ }^{36}$

La Provança fue todo un éxito. No hubo necesidad de llevar a cabo la tala de palmas. Las autoridades centrales comprendieron el perjuicio que causarían al vecindario colimense y este gobierno local se adjudicó un triunfo que más adelante utilizaría a su favor. Colima, un territorio en constante zona de riesgo por amenazas volcánicas, temblores "de tierra" y huracanes, supo aprovechar sus adversidades naturales para jugar estratégicamente en el terreno político y obtener a cambio concesiones de índole económica.

Esto es evidente en los fenómenos naturales que acontecieron a lo largo del siglo XVII. Después de informar al virrey sobre los desastres que huracanes y terremotos causaban entre la población, venía una súplica para que les permitieran continuar la fabricación del vino de cocos y, con ello, sobrellevar los estragos.

34 Sevilla, Provança, págs. 85-86.

35 Enciso Contreras, José: Zacatecas en el siglo XVI: Derecho y sociedad colonial, Ayuntamiento de Zacatecas-Universidad de Alicante-Instituto Zacatecano de Cultura Ramón López Velarde, Zacatecas, 2000, pág. 438.

36 Sevilla, Provança, págs. 85-86. 
Un fuerte huracán azotó la provincia colimense en el año de 1626. La cantidad de agua que cayó en ese entonces devastó lo que quedaba de sembradíos de cacao que, como se mencionó anteriormente, ya habían perdido la importancia que alguna vez tuvieron. Un año más tarde, el Cabildo de la villa de Colima se dirigió al virrey don Rodrigo Pacheco y Osorio para solicitarle una licencia de comercialización del aguardiente de palmas, argumentando que los habitantes estaban en extrema pobreza a causa de las intensas lluvias que habían arruinado las haciendas de cacaotales. El marqués de Cerralvo otorgó, en 1627, la primera de una larga serie de licencias que permitirían a los vecinos el libre trajineo del vino.

Después del consentimiento del citado virrey vendría un verdadero auge en el comercio de esta bebida. Simplemente, en 1631, los colimenses ya habían producido 6,250 botijas peruleras, que equivalían a 3.000 litros, aproximadamente.$^{37}$ En un vecindario que para mediados del siglo XVII no rebasaría los 150 vecinos, la mayoría de ellos tenían haciendas "de beneficio" para hacer vino de cocos. Hacia 1644, se registraron ochenta y dos propietarios de haciendas de palmas (ver Tabla 1).

De los hacendados que se muestran en esa Tabla, destacan algunos miembros de la corporación municipal, como los regidores Gregorio Fernández de Tene y Juan Álvarez Pereira, los alféreces Juan Ochoa de Vitoria y Pedro de Ceballos, el depositario general Pedro López de Salazar y el escribano Clemente Hidalgo de Agüero. Hay también algunos nombres como los de Alonso y Antonio Carrillo de Guzmán, Juan y Cristóbal de Solórzano, Rodrigo de Brizuela y Alonso Maldonado, quienes desempeñaron cargos públicos en la localidad en otros periodos. Asimismo, entre los propietarios destacan los "indios chinos" Miguel Pano, Sebastián de la Cruz, Juan de Triana, Francisco Ramos y Nicolás Mananquel.

Cuando finalizaba el plazo de los permisos para fabricación del aguardiente, los vecinos ya estaban prestos a solicitar el siguiente. Fue así como la villa de Colima, en ocasiones a través del Cabildo y otras a nombre de algún vecino, suplicaba a los virreyes de turno la renovación de licencias, consiguiendo prórrogas en los años de 1644, 1653, 1664, 1668, 1691 y 1699.

37 Reyes, La antigua provincia, pág. 160. 


\section{TABLA 1}

\section{PROPIETARIOS DE HACIENDAS DE PALMAS EN COLIMA, $1644^{38}$}

1. Capitán Gabriel de Trejo

2. Juan López de Anca

3. Miguel Pano

4. Nicolás Florido

5. Sebastián de la Cruz

6. Lic. Juan Fernández Nieto

7. Gregorio Fernández de Tene

8. Juan de Velasco

9. Alonso Carrillo de Guzmán

10. Antonio de Solórzano

11. Doña Mariana de Moscoso

12. Bartolomé Rodríguez

13. La hacienda de Aguacatitlán

14. Capitán Rodrigo de Brizuela

15. Marcos Franco

16. Esteban Meléndez

17. Doña Luisa de Ávila

18. Joseph de Lavayen

19. Bachiller Diego Correa

20. Tomás de Solórzano

21. Doña Marina Tineo (viuda)

22. Diego de Quiroz

23. Hernando Martel

24. Domingo Martel

25. Doña Mariana de Arellano (viuda)

26. Doña Isabel de Villanueva

27. Martín Vela

28. Pedro López de Salazar

29. Juan de Solórzano

30. Clemente Hidalgo de Agüero

31. Cristóbal Arias

32. Cristóbal de Solórzano

33. Juan de Herrera

34. Francisco López Troncoso

35. Juan de Triana

36. Francisco Ramos

37. Juan de Contreras

38. Juan del Campo

39. Bartolomé Núñez

40. Baltasar Castelán

41. Ginés Gallardo
42. Los menores de Juan de San Pedro

43. La viuda de Diego Rodríguez

44. Jerónimo Fernández

45. Joseph G. Durán

46. Agustín de Luna

47. Pedro de Ceballos

48. Roque de Llarca

49. Miguel Fernández

50. Juan Jiménez de Nava

51. Doña María de Guzmán

52. Alonso Maldonado

53. Doña Francisca de Nava (viuda)

54. Juan Ponce de León

55. Doña Francisca de Guzmán

56. Jerónimo Carrillo

57. Alonso de la Barra

58. Andrés Ramos

59. Doña María de Monsalve y Diego Torres

60. Juan Ochoa de Vitoria

61. Jerónimo de Vitoria

62. Juan de Torres

63. Pedro Ramírez

64. Diego de Castañeda y doña Inés de Monroy

65. Juan Álvarez Pereira

66. Francisco Clemente Larios

67. Simón de Zendejas

68. Juan de la Torre

69. Antonio Pineda

70. Diego Moreno

71. Hernando García

72. Bárbola de Angulo

73. Antonio Carrillo de Guzmán

74. Pedro Sánchez

75. Nicolás de Biana

76. Juan del Valle

77. Blas de Mesina

78. Francisco de Vargas

79. Nicolás Mananquel

80. Custodio Álvarez

81. Francisco Martín de Campos

82. Doña Isabel de la Vega (viuda)

38 Guedea, Las haciendas, págs. 65-67. 


\section{La rivalidad con la Nueva Galicia}

Para la sorpresa de los vecinos de Colima, en el año de 1637 se creo el estanco de vino de cocos y mezcal en la ciudad de Guadalajara. En un intento de controlar el creciente comercio del vino de cocos en la jurisdicción de la Real Audiencia de la Nueva Galicia, hasta entonces fuera de la órbita permitida para los fabricantes de Colima, las autoridades neogallegas otorgaron los permisos necesarios para otorgar la concesión del estanco. Este fue un golpe significativo para los fabricantes de Colima porque, aun cuando carecían del permiso para comercializarlo en territorio neogallego, es evidente que lo introducían de contrabando.

La preocupación que causó el establecimiento del estanco del vino de cocos y mezcal en Guadalajara motivó, nuevamente, la actuación del Cabildo, atento al posible perjuicio que esto podría acarrear a sus intereses económicos. De esta manera y con apoyo del entonces sargento mayor de la provincia, don Félix Candela, se determinó que "habiéndose conversado en el cabildo y ayuntamiento desta villa... hay necesidad al bien público desta provincia en que por ahora ninguna persona de ninguna calidad que sea saque en su recua vino de cocos para la ciudad de Guadalajara, ni le venda ni entregue ni remita de ninguna fuerza, y esto hasta que otra cosa se provea y mande". ${ }^{39}$

Se prohibió entonces que ninguna persona, de ninguna calidad, vendiera ni remitiera vino de cocos en la ciudad de Guadalajara sin expresa licencia, intentando por alguna vía controlar las cantidades que salían a esta ciudad. Hubo restricciones también para quienes trajinaban el aguardiente a la provincia de Michoacán, imponiéndose cierto tipo de fianzas para su comercialización. Así, el 2 de noviembre de 1637, se levantó una relación de las personas que lo distribuían fuera de la provincia de Colima, quienes juraron que no llevarían su mercancía a Guadalajara (ver tabla 2).

En la Tabla 2 se observa la participación del alcalde ordinario Bartolomé Bravo y del regidor Alonso de Vitoria como fiadores de tratantes, además de la Familia Fernández de Tene, quienes ocuparon cargos en la corporación municipal en otros periodos. Se estableció una estrecha vigilancia para que el decreto anterior se cumpliera, lo que derivó en denuncias por introducir el aguardiente de palmas en la jurisdicción neogallega. ${ }^{40}$

39 AHMC, caja 14, exp. 3. Colima, 1 de diciembre de 1637.

40 Por citar un ejemplo, el alcalde mayor de Colima, Cristóbal de Lugo, ordenó averiguar el caso de un mulato libre llamado Juan Paz por salir de la provincia de Colima con cargas de vino de cocos rumbo a la ciudad de Guadalajara y otras partes, en contravención del auto que estaba publicado: AHMC, caja 19, exp. 23. Colima, 16 de noviembre, 1640. 


\section{TABLA 2}

TRATANTES DEL VINO DE COCOS FUERA DE LA PROVINCIA DE COLIMA

\begin{tabular}{|c|c|c|}
\hline Tratantes & Cargas de vino & Fecha \\
\hline Miguel de Castañeda, fiador de Juan de Campos & 3 cargas & 4 de noviembre, 1637 \\
\hline \multicolumn{3}{|l|}{ Bartolomé Bravo, vecino y alcalde ordinario de Colima, } \\
\hline Francisco Martín de Campos, fiador de Antonio Barradas & - & 4 de noviembre, 1637 \\
\hline Antonio de Aragón, fiador de Cristóbal de Aguirre & 10 cargas & 5 de noviembre, 1637 \\
\hline Joseph de Lavayen, fiador de José Durán & 12 cargas & 14 de noviembre, 1637 \\
\hline Nicolás de Mesina, fiador de José de Morales & 9 cargas & 15 de noviembre, 1637 \\
\hline Juan López de Ansa, fiador de Andrés de Mesa & 11 cargas & 17 de noviembre, 1637 \\
\hline Miguel de Castañeda, fiador de Juan de Velasco & 23 cargas & 17 de noviembre, 1637 \\
\hline Blas de Mesina, fiador de Cristóbal de Aguilar & 2 cargas & 21 de noviembre, 1637 \\
\hline Jerónimo Tello de Carvajal, fiador de Eligio de Carvajal & 10 cargas & 24 de noviembre, 1637 \\
\hline Jerónimo de Sotomayor, fiador de Andrés de Trujillo & 4 cargas & 25 de noviembre, 1637 \\
\hline Hernando de Solórzano, fiador de Martín de Olagres & 3 cargas & 25 de noviembre, 1637 \\
\hline Jacinto Gutiérrez, fiador de Juan Martín Manzano & 6 cargas & 27 de noviembre, 1637 \\
\hline Francisco Martín de Campos, fiador de Diego Sánchez & 10 cargas & 26 de noviembre, 1637 \\
\hline \multicolumn{3}{|l|}{ Gregorio Fernández de Tene, fiador de Gregorio } \\
\hline Fernández de Tene "el Mozo", su hijo & 5 cargas & 28 de noviembre, 1637 \\
\hline Miguel de Castañeda, fiador de Diego López, mulato libre & 10 cargas & 28 de noviembre, 1637 \\
\hline Pedro Gómez de Olvera, fiador de Alonso de Estrada & 20 cargas & 28 de noviembre, 1637 \\
\hline Alonso de Vitoria, regidor, fiador de Bartolomé Chavarín & 8 cargas & 30 de noviembre, 1637 \\
\hline Miguel de Castañeda, fiador de Lope de Cobián & 8 cargas & 4 de diciembre, 1637 \\
\hline Antonio de Aragón, fiador de Bartolomé de Molinedo & 9 cargas & 6 de diciembre, 1637 \\
\hline Jerónimo de Sotomayor, fiador de Mateo de Alfaro & 15 cargas & 6 de diciembre, 1637 \\
\hline Francisco Mendoza, fiador de Antonio Pinero & 5 cargas & 8 de diciembre, 1637 \\
\hline Jorge Posviana (?), fiador de Rodrigo de Paneda & 10 cargas & 13 de diciembre, 1637 \\
\hline Joseph de Lavayen, fiador de Francisco Núñez & 5 cargas & 15 de diciembre, 1637 \\
\hline Miguel de Castañeda, fiador de Juan Francisco, mulato & 5 cargas & 18 de diciembre, 1637 \\
\hline Blas de Mesina, fiador de Diego Flores & 6 cargas & - \\
\hline
\end{tabular}

Fuente: AHMC, caja 14, exp. 3. Colima, 1 de diciembre de 1637.

La medida adoptada por el Ayuntamiento de prohibir el comercio del vino de cocos con Guadalajara, salvo expresa licencia, debió favorecer, sin embargo, a unos cuantos vecinos de la localidad. Un ejemplo muy claro de ello fue Clemente Hidalgo de Agüero, escribano público del Cabildo de Colima y uno de los fabricantes más prominentes. El escribano enviaba a Francisco García Vidal, vecino de Guadalajara y en quien se había rematado el estanco de vino de cocos y mezcal, 1,265 arrobas de vino de cocos que se producían en su hacienda, y los tiempos de entrega eran los siguientes: "este mes de enero de 1638, doscientas y treinta arrobas, y otras dos- 
cientas y treinta en el mes de mayo, otras tantas el mes de septiembre deste dicho año". ${ }^{41}$

Hacia 1670, el vino de cocos se comercializaba legalmente sólo en territorio bajo la jurisdicción de la Nueva España. La Nueva Galicia permanecía, hasta entonces, vedada oficialmente. Una vez más, la intervención del Cabildo de Colima fue clave para presionar a los oidores de Guadalajara y lograr, en 1672, que la Real Audiencia de Nueva Galicia otorgara el permiso de introducir el vino de cocos en su estanco, apelando a que el Protomedicato de la Nueva España había decretado, muchos años antes, que usada con moderación la bebida era saludable y medicinal. ${ }^{42}$

Ese año se hicieron pregones para que el vino de cocos de Colima se vendiera públicamente en tabernas y tiendas, por un tiempo de cuatro años, y el estanco se remató en Miguel Thomas para el periodo de 1672 y $1673 .{ }^{43}$ El acuerdo establecía además que el precio del cuartillo de aguardiente sería de dos reales y que los arrieros que trajinaran el vino de cocos y pasaran con él en los contornos de Guadalajara y ocho leguas alrededor debían de manifestarlo en el estanco.

\section{La justicia clemente}

Cada vez que el Cabildo de Colima o alguno de sus vecinos solicitaba al virrey una prórroga para fabricar el vino de cocos, se aludía a la pobreza del vecindario, a los daños causados por el paso de algún huracán, o bien, a los perjuicios ocasionados por los frecuentes "temblores de tierra". Este hecho, nombrado en el ámbito jurídico como "justicia clemente", fue aprovechado hábilmente por la localidad colimense.

Si se quiere hacer una recapitulación de las formas en que el Cabildo de Colima y sus vecinos solicitaban a las autoridades centrales el permiso del libre trajineo del vino, debe recordarse que desde 1612, año en el que la Real Audiencia de México ordenó la tala total de los palmares de la provincia, los argumentos para defender las plantaciones se basaron en la pobreza que a esta villa traería la ejecución del mandamiento. En 1627, cuando se otorgó por primera vez la licencia de elaborar vino de cocos, se

41 AHMC, caja 17, exp. 3. Colima, 1637.

42 AGI, Guadalajara, 15, R. 1, N. 26. Guadalajara, 19 de enero de 1672.

43 Ibidem. 
manifestó que un año antes un huracán había arrasado las haciendas de cacao y que la única solución al desastre sería el sustento de los vecinos mediante el vino de cocos.

Curiosamente, la petición de prórroga en 1668 tuvo los mismos argumentos. El marqués de Mancera otorgó al Cabildo, justicia y Regimiento de la villa de Colima, la concesión "para que por tiempo de seis años pueda hacer y vender el vino de cocos en todas las partes y lugares desta Nueva España con que no sea a indios". ${ }^{44}$ El citado virrey había recibido una relación que aludía a la ruina en que se encontraba la villa de Colima por los temblores que había padecido recientemente, "en cuya atención me suplicó el dicho cabildo justicia y regimiento de dicha villa le concediere licencia para que por tiempo de diez años puedan vender el dicho vino de cocos y trajinarlo para conservación de los vecinos y reparo del daño recibido". ${ }^{45}$ Pero la extensión del permiso no fue por diez, sino sólo por seis años más.

Asimismo, en 1691 los vecinos de Colima comisionaron a Baltasar de la Vega para que, en nombre de ellos, informara al virrey sobre los daños que habían causado los terremotos de 1690 y 1691 y, a partir de entonces, solicitar el acostumbrado permiso de elaborar aguardiente de palmas. Así, el capitán de la Vega,

vecino y casado en la villa de Colima, enviado con poder de los vecinos della a los pies de vuestra excelencia a que le dé noticia del segundo terremoto de tierra a que nuestro señor envió el día de San Gregorio, doce de marzo deste año, que se juzgó por su terribilidad por el juicio final que duró tiempo de un Ave María, la fuerza que acabó de postrar a una villa antigua y [...] compuesta de buenos frutos, echando por el suelo todo lo que había podido reedificar del primer terremoto, templos, casas a veintitrés de febrero del año de noventa, a expensas del crecido trabajo que ahora no volviese a ejecutar lo propio, derribando haciendas de trapiches, haciendo pedazos formas y azúcares y mieles por los suelos, por ser el tiempo de las moliendas. El terremoto segundo que sucedió y las haciendas de palmas de hacer vinos de cocos tan medicinal, en muchas partes perdidas sus cosechas derramadas en el todo por los suelos y sus vasijas hechas pedazos, pérdidas muy sensibles para muchos siglos, y los temblores continuándose de noche y día sin faltar... ${ }^{46}$

Después de estas noticias, se informó al virrey que aquella villa de Colima se dedicaba a fabricar vino de cocos, "tan saludable y medicinal" como "tantas veces" lo tenía declarado el Protomedicato de la Real

\footnotetext{
44 AGN, Ordenanzas, vol. 5, exp. 21, f. 15. México, 15 de mayo de 1648.

45 Ibidem.

46 AGN, Indiferente virreinal, caja 2949, exp. 52, f. 1v-2. México, 23 de abril de 1691.
} 
Universidad, que los conventos tenían su "pie de altar" en las haciendas porque de ahí se pagaban los diezmos de la Iglesia y los clérigos tenían fundadas sus capellanías a título de las haciendas de palmas. ${ }^{47}$

Pero en el fondo, a donde el capitán de la Vega quería llegar era a denunciar que diversos ministros de justicia amenazaban a los pobres vecinos que trajinaban la bebida hasta la ciudad de México, en un viaje de ciento veinte leguas de camino. A decir del capitán, desde hacía dieciocho años los alcaldes mayores de Xiquilpa, Chichotla y Tingüindín les hacían pagar cuatro pesos por carga de vino, además de que les pedían una botija de vino para cada uno de estos alcaldes mayores, "por cuya jurisdicción es muy ordinario pasar que han sido causa menoscabarse las haciendas referidas". ${ }^{48}$ Los moradores de la villa de Colima pedían entonces que el virrey los mirase "con ojos de piedad" y ordenara que el vino de cocos ingresara públicamente en la Aduana de la ciudad de México, pagando los reales que por derecho se dispusieren, y así evitar todas las vejaciones y agravios de que eran objeto.

Como era de esperar, la licencia fue concedida el diez de mayo de $1691{ }^{49}$ Cuando ésta hubo de claudicar, nuevamente, el capitán Baltasar de la Vega y el bachiller don Joseph de Alvarzusa, en nombre de los vecinos de Colima, acudieron al entonces virrey de la Nueva España, don José Sarmiento y Valladares, conde de Moctezuma, para suplicarle la acostumbrada prórroga. En esta ocasión, los argumentos para recibir la merced fueron los temblores, los piratas y hasta un incendio. Como lo venían haciendo en ocasiones previas, los colimenses dieron cuenta de la importancia que tenía el vino de cocos en la economía la de provincia, pues era el principal sustento no sólo de los vecinos, sino también de las instituciones religiosas.

Mencionaron al virrey que era justo permitir el libre comercio del aguardiente de palmas "así porque mira a las causas pías y eclesiásticas como a los reales haberes y bienes de la república". ${ }^{50}$ Es decir, miraba a las causas pías porque a través de sus ventas se mantenían conventos mediante diezmos, capellanías y rentas, mientras Su Majestad gozaba de los "rea-

47 Ibidem, f. 3.

48 Ibidem, f. $3 \mathrm{v}$.

49 AGN, Indiferente virreinal, caja 6112, exp. 5, f. 1. México, 21 de mayo de 1699. En este documento se hace referencia a la licencia que se otorgó a los vecinos de Colima sobre el libre trajín del vino, en 1691.

50 Ibidem, f. 2. 
les haberes" por medio del concepto de alcabalas y servicio de aduana. Prohibir el vino de cocos, según de la Vega y Alvarzusa, traería consecuencias desastrosas, pues la provincia quedaría desamparada y las invasiones del enemigo pirata serían perjudiciales para el reino,

y más hoy que se llora dicho puerto con las adversidades que ha padecido por la continuación que hizo en sus costas el pirata tiempo de cinco años. A que se agregan las calamidades causadas de los repetidos temblores, tales que postraron templos y casas por el suelo, a que se siguieron los daños generales y allí más crecidos de epidemia y hambre, y por último ahora los diez de abril del año próximo pasado de noventa y tres, el incendio cuya voracidad consumió veinte y seis casas de familias que se habían reedificado con que se abrasaron todos los géneros y bienes de los vecinos y se perdieron gruesas cantidades que eran las vasas de sus comerciantes quedando con este estrago extremadamente destruidos y permanecerán así si no les concede vuestra excelencia el recurso y facultad de tratar en dichos vinos... ${ }^{51}$

Hacia finales del siglo XVII, los asentistas del pulque en la capital del Virreinato comenzaron a presionar a los tratantes de vino de cocos, en una franca competencia por el mercado. Los asentistas pidieron que el vino de cocos de Colima que entraba a la capital pagara el mismo impuesto que el primero, y que de lo contrario se prohibiera su ingreso. ${ }^{52}$ En algunas tabernas capitalinas, como en la de doña Leonor García, el vino de cocos era muy solicitado por los clientes. Esta señora era viuda y dueña de una tienda de vinos con la que se ganaba su sustento y el de una hija doncella. En diciembre de 1690 hizo una petición para poder vender "el vino y aguardiente que llaman de $\operatorname{cocos}{ }^{53}$ sin que por ello recibiera amonestación, pues apelaba al derecho concedido a los vecinos de Colima para poder distribuirlo.

\section{El declive del vino de cocos}

La mala fama del vino de cocos no la quitarían ni los protomédicos de la Nueva España. En el año de 1680 el cura de Arantzan, Michoacán, se manifestó en contra de este aguardiente porque, a su parecer, "era el mal primero y fuente de muchos y mayores que él [...] Para esto tienen a

51 Ibidem, f. 2-2v.

52 Guedea, Las haciendas, pág. 68.

53 AGN, Indiferente virreinal, caja 6366, exp. 48. 
Colima, que con sus palmas y vino de cocos que destila, tiene destruida esta provincia"..$^{54}$

En 1724, el virrey Juan de Acuña, marqués de Casafuerte, emitió una orden para combatir los "vinos de la tierra" y estableció "que ninguna persona, sea de la hierarchia, dignidad, y elevación que fuere, aunque sea caballero, militar, noble o plebeyo, español, indio, mulato, negro, mestizo, lobo, o coyote [...] pueda inventar, fabricar, ni introducir" bebidas de la tierra. ${ }^{55}$

La situación adversa propició un declive en la producción del vino de cocos, de manera que a finales del siglo XVIII se hablaba ya, escasamente, de esta industria. La sal, el arroz, el chicle, las maderas y el limón vendrían a ocupar los espacios económicos, en los cuales circulaban local y regionalmente..$^{56}$ 81-100.

56 Olveda, Jaime: "Colima a finales del siglo XVIII”, Secuencia, 29, México, 1994, págs. 